\title{
Desempeño térmico de cerramientos de tierra alivianada. Posibilidades de aplicación en el territorio peruano
}

Thermal performance of light earth enclosures. Possibilities of its application in the Peruvian territory

\section{Martin Wieser}

Pontificia Universidad Católica del Perú, PUCP. Lima, (Perú)

Departamento de Arquitectura

Silvia Onnis

Pontificia Universidad Católica del Perú, PUCP. Lima, (Perú)

Departamento de Arquitectura

\section{Giuseppina Meli}

Pontificia Universidad Católica del Perú, PUCP. Lima, (Perú)

Departamento de Arquitectura

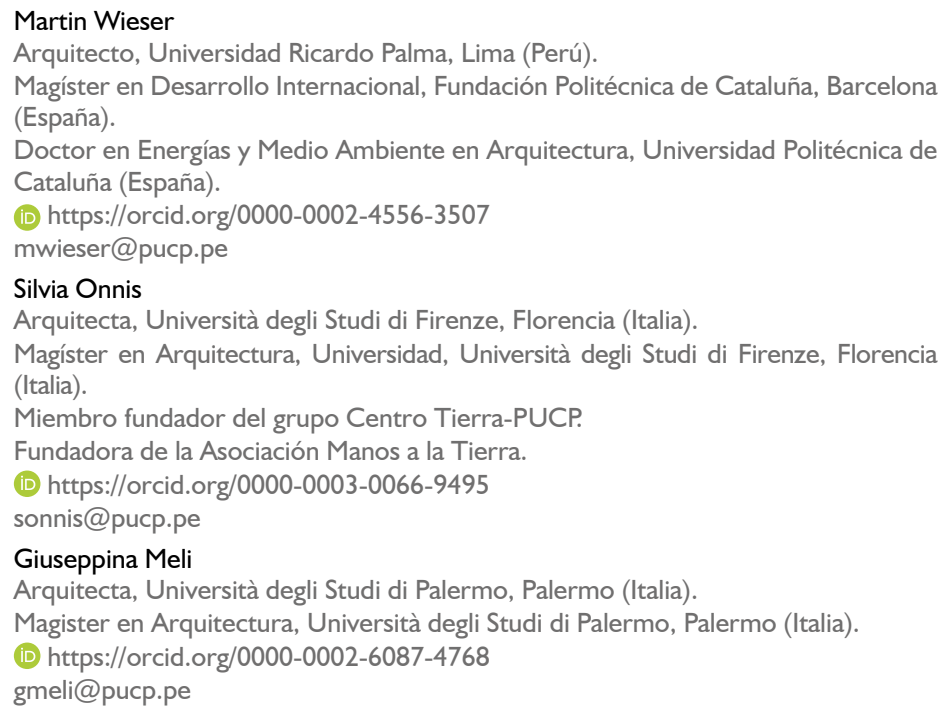

Wieser, M., Onnis, S., \& Meli, G. (2020). Desempeño térmico de cerramientos de tierra alivianada. Posibilidades de aplicación en el territorio peruano. Revista de Arquitectura (Bogotá),22(I), 164-I74. https://doi.org/10.14718/ RevArq.2020.2633

\section{Introducción}

\section{Resumen}

Las soluciones constructivas tradicionales y contemporáneas han demostrado tener serias limitaciones en cuanto a la solución del déficit cualitativo y cuantitativo de la vivienda y el equipamiento; las evidencias del desempeño térmico son igualmente desalentadoras. Por tal razón, en el presente estudio se indaga sobre la capacidad de la tierra alivianada para brindar confort térmico en los edificios, considerando los diferentes climas del territorio peruano y comparándola con los sistemas constructivos más comunes en el medio: el adobe y la albañilería de ladrillo. A partir de la caracterización previa de las cualidades térmicas de los componentes, de la realización de simulaciones térmicas dinámicas, y comparando el desempeño de diferentes prototipos digitales, se identificaron las ventajas de la tierra alivianada para brindar confort térmico en las edificaciones; el buen desempeño del material se atribuye a su marcado equilibrio entre una masa térmica media y una conductividad térmica relativamente baja. Adicionalmente, se destacan las ventajas ecológicas debido a la utilización de materiales naturales, renovables y biodegradables en la composición del sistema constructivo propuesto.

Palabras clave: arquitectura bioclimática; arquitectura sostenible; climatización pasiva; confort térmico; inercia térmica; simulación térmica; sistema constructivo; transmitancia térmica

\section{Abstract}

Traditional and contemporary construction systems have shown serious limitations in the solution of the qualitative and quantitative deficit of housing and equipment. Evidence of thermal performance is equally discouraging. That is why this study enquiries about the ability of light earth to provide thermal comfort in buildings, considering the different climates of the Peruvian territory and comparing it with the most common construction systems in the environment: adobe and brick masonry. As of the previous characterization of the components' thermal qualities, the carrying out of dynamic thermal simulations and comparing the performance of different digital prototypes, the virtues of light earth to provide thermal comfort in buildings were identified. The good performance of the material is attributed to the marked balance between a medium thermal mass and a relatively low thermal conductivity. It is the only one that meets the requirements of the current Peruvian energy efficiency standard in the case of colder climates. Additionally, the ecological advantages associated to the use of natural, renewable and biodegradable materials in the composition of the proposed construction system are highlighted.
\end{abstract}

Keywords: bioclimatic architecture; sustainable architecture; passive air conditioning; thermal comfort; thermal inertia; thermal simulation; construction system; thermal transmittance
El presente estudio se enmarca en un proyecto de investigación financiado por el Servicio Nacional de Capacitación para la Industria de la Construcción (SENCICO), el Concejo Nacional de Ciencia, Tecnología e Innovación Tecnológica (CONCYTEC) y la Pontificia Universidad Católica del Perú (PUCP), y el cual contempla la validación estructural y constructiva de un sistema compuesto de una estructura de madera y cerramientos de tierra alivianada, así como la construcción de un prototipo a escala real. La investigación que se presenta pretende anticipar y validar específicamente el desempeño térmico de una construcción con una envolvente de tierra alivianada en los diferentes ámbitos climáticos del territorio peruano.

En el Perú y en Latinoamérica persiste un enorme déficit cuantitativo y cualitativo de vivienda y equipamiento (Bouillon et al., 2012). A pesar de que la región ha logrado un crecimiento económico sin precedentes a lo largo de las últimas décadas, ni las políticas públicas ni las iniciativas privadas han sido capaces de resolver dicha carencia. Frente a una población crecientemente urbana, en el caso específico del Perú, las soluciones constructivas de los programas de vivienda y equipamiento se limitan casi exclusivamente al uso del ladrillo y del concreto armado. Una segunda alternativa es el uso de estructuras ligeras de madera o fibrocemento con techos de planchas onduladas. En todos los casos se identifica que el principal objetivo es reducir los costos de la edificación, sin contemplar aspectos relativos al 
impacto de la construcción en el medio ambiente o a la propia habitabilidad de los edificios.

Resulta necesario ofrecer opciones constructivas que, reconociendo la gran diversidad climática del territorio peruano y sin renunciar al bajo costo, ofrezcan una estructura sismorresistente, generen un bajo impacto en el medio ambiente y provean un adecuado confort térmico a sus ocupantes. En tal sentido, se valora el potencial de las técnicas constructivas mixtas con estructura de madera (capacidad antisísmica) y cerramientos de tierra alivianada (capacidad térmica), ya que representan una alternativa con muchas posibilidades para enfrentar el problema expuesto.

Aun cuando gran parte del territorio peruano se encuentra en zonas de gran actividad sísmica, y si bien muchas técnicas y soluciones constructivas tradicionales, como las shicras ${ }^{1}$ en los cimientos o la quincha ${ }^{2}$ en las paredes, responden de manera adecuada a estas condicionantes, no existen precedentes en el Perú sobre el uso de elementos de tierra alivianada en los edificios. Las técnicas de construcción con tierra más comunes en el medio, y que mantienen aún cierta vigencia, como el adobe, el tapial o la quincha, han utilizado siempre mezclas de densidades relativamente altas.

La tierra alivianada (light earth, en inglés), como definición, es aquella mezcla de masa de tierra con una proporción alta de agregados ligeros, generalmente fibras de gramíneas, y cuya densidad final es menor a $1200 \mathrm{~kg} / \mathrm{m}^{3}$. El uso de recursos locales, naturales, renovables y biodegradables para la concepción de los elementos presenta a este material como una alternativa potencialmente económica y de bajo impacto en el medio ambiente. Así mismo, la presencia de gran cantidad de fibras naturales en su composición genera vacíos estancos en su interior, lo que reduce considerablemente la conductividad térmica a través del material y sacrifica solo ligeramente la inercia térmica del mismo, en comparación con mezclas de tierra convencionales. Las propiedades mecánicas y físicas del material lo convierten en la actualidad en una alternativa válida para ser considerada.

En cuanto a los estudios que se han hecho sobre la tierra alivianada, y específicamente acerca de las propiedades térmicas de dicho material, sobresale el documento publicado por Franz Volhard (2016), quien recopila valores de conductividad térmica y calor específico de muestras de diferentes densidades, a partir de diversas normas e investigaciones. Se han venido desarrollando ocasionalmente estudios adicionales sobre el tema,

1 Bolsas confeccionadas a partir de tejidos de fibra natural que contienen piedras de diferentes tamaños. Se ponían ocasionalmente en las bases de los muros de las pirámides prehispánicas, para disipar la fuerza de los sismos.

2 Sistema constructivo en el que los muros están conformados por una estructura de madera, que, a su vez, contiene un tejido de caña o carrizo, y el cual es finalmente recubierto con barro. con un interés particular en el cáñamo como agregado natural; sobresalen en ese sentido los trabajos de Busbridge y Rhydwen (2010) y de Vinceslas, T. et al. (2019). No se han desarrollado estudios en ese tema específico en el ámbito nacional ni en el latinoamericano, salvo el que sirve de precedente al presente estudio, dentro del marco de una investigación sobre la mejora de las prestaciones térmicas del sistema constructivo tradicional de la quincha (Wieser, Onnis y Meli, 2018).

Identificadas las propiedades térmicas de la tierra alivianada, y a partir de las posibilidades que proveen las nuevas herramientas informáticas de simulación térmica, capaces de calcular y predecir con un alto grado de fiabilidad el desempeño energético de una edificación, ha sido posible realizar el estudio de forma comparativa, considerando tanto las soluciones convencionales como aquellas concebidas a base de tierra alivianada. Los resultados permiten no solo identificar el potencial del sistema propuesto, sino también cuestionar la forma como se construye actualmente en el medio, insensible a la diversidad climática local, con las consecuencias económicas, ecológicas y de confort que eso conlleva.

\section{Metodología}

Para la valoración del comportamiento térmico de la tierra alivianada como envolvente de edificios en el Perú, se describen en primer lugar los diferentes climas en los que se evaluará el sistema y se eligen las ciudades representativas para hacer las simulaciones térmicas dinámicas. La elección de dichas ciudades se ha realizado procurando que estas coincidan con las características climáticas típicas de las diferentes zonas, además de la condición de disponer de datos fiables de dichos emplazamientos. Se ha procurado, igualmente, su cercanía relativa en el territorio, además de su ubicación en la zona sur del país, donde la mayor latitud condiciona una mayor oscilación térmica estacional.

La necesidad de insertar datos climáticos en el software de simulación requirió obtener datos meteorológicos horarios de un año típico de cada una de las ciudades en formato 'epw's ${ }^{3}$ No existe una fuente local oficial de la que se pueda obtener esta información en dicho formato, por lo que se recurrió a diversas fuentes externas. Los archivos de las ciudades de Arequipa y Cuzco son obtenidos de la página web de EnergyPlus ${ }^{4}$, del Departamento de Energía de los Estados Unidos (2019); los de las ciudades de Ilo, Tacna y

3 Un archivo con extensión 'epw' hace referencia a formato de clima de EnergyPlus (EnergyPlus Weather Format). Contiene la información meteorológica de un año típico de una localidad específica.

4 El programa informático Energy Plus es una herramienta de cálculo térmico dinámico desarrollada por el Departamento de Energía de los Estados Unidos de Norteamérica. Su fiabilidad está ampliamente reconocida en el ámbito académico y comercial. Provee también información climática gratuita de diversas ciudades en el mundo. https://energyplus.net/ weather 
Juliaca, de la página Climate. OneBuilding 5 , y los de la ciudad de Moquegua, a partir de la interpolación realizada por el software Meteonorm 7.06 . En todos los casos, los datos promedio de dichas fuentes se compararon con los presentados en el portal institucional del Instituto Geofísico del Perú (2018), y así se pudo comprobar su validez.

En segundo lugar, para cada una de las ciudades se identifican los límites de temperaturas interiores que delimitan situaciones de confort térmico a partir de la teoría del confort adaptativo, para edificios acondicionados de forma pasiva (en inglés, free running buildings). En el presente trabajo se considerarán los estudios desarrollados por los autores De Dear y Brager (1998), los cuales confirman la relación estrecha que hay entre las condiciones de temperaturas medias exteriores mensuales y la posibilidad de lograr el confort térmico, en la medida de la capacidad de los usuarios para ajustar sus comportamientos y de su propia adaptación psicológica al medio.

Posteriormente, se presentan las propiedades térmicas de los materiales que conforman los muros y los techos que van a considerarse en los cálculos y las simulaciones posteriores, con énfasis en las de la tierra alivianada. A continuación se describen los detalles, las características geométricas y los patrones de uso del prototipo que se va a simular.

Como primera medida, con los datos previamente identificados se calculan los valores de transmitancia e inercia térmicas de las propuestas elegidas de muros y techos, lo que permite una primera valoración de los sistemas constructivos. Dichos valores se deducen con el apoyo de la herramienta informática Opaque 3.07, a partir de los datos del espesor, de la conductividad térmica, del calor específico y de la densidad de los materiales que lo conforman.

En segunda instancia, se presentan los resultados de las simulaciones dinámicas realizadas en cada uno de los climas, considerando ambientes

5 Climate.OneBuilding es un repositorio virtual de data climática de acceso libre. Para el caso del Perú, se dispone datos meteorológicos de un total de 30 estaciones. http://climate. onebuilding.org/default.htm

6 Meteonorm Software es un programa informático desarrollado por la compañía suiza Meteotest, capaz de brindar y generar datos climáticos de cualquier lugar del mundo, tanto de una base de datos como de la interpolación de datos de estaciones cercanas. https://www.meteonorm.com/

y ciudades representativas consideradas para el análisis de desempeño térmico.

Fuente: elaboración propia (2019). con ausencia de equipos de climatización artificial. Dichas simulaciones se realizan mediante la herramienta informática Design Builder 4.5 ${ }^{8}$. Los resultados del comportamiento de la temperatura interior se valorarán finalmente en función de la capacidad para proveer confort térmico a los usuarios.

\section{Resultados}

\section{La diversidad climática del Perú}

La enorme diversidad climática del Perú se debe en gran medida a la presencia de la cordillera de los Andes; esta no solo condiciona emplazamientos de diversas altitudes, sino que separa las masas de aire de la parte occidental, asociadas a las aguas frías de la corriente de Humboldt, de las masas cálidas y húmedas de la parte oriental de la selva amazónica. La única condición constante, debido a la cercanía con la línea ecuatorial, es la alta radiación, que incide en todo el territorio a lo largo del año.

Tomando como base la clasificación propuesta para efectos de diseño por Wieser (2011), el país se puede dividir en siete grandes zonas climáticas. La primera corresponde a gran parte de la franja costera desértica peruana, en la que vive casi la mitad la población, incluyendo la ciudad de Lima; tiene un clima subtropical, expuesto a las brisas marinas frescas, influenciadas por las aguas frías del océano, con temperaturas de aire bastante moderadas, de baja oscilación térmica diaria y estacional, de humedad relativa moderadamente alta y muy escasas precipitaciones. La excepción es una pequeña franja de costa al norte del país, en la que existe un clima tropical, debido a la presencia de corrientes marinas cálidas.

Una segunda zona climática es la desértica, ligeramente alejada del litoral, y en la que las brisas marinas han perdido fuerza, por lo cual la oscilación térmica es de moderada a alta, con días cálidos y noches frescas, humedad relativa moderada o baja, radiación solar más intensa y precipitaciones casi inexistentes.

La tercera zona es la continental templada, en la vertiente occidental de la cordillera de los Andes, y que, con una mayor altitud y más lejana del océano, se ubica entre los 1000 a 2300 msnm. Tiene una alta oscilación térmica diaria, con días

8 El programa informático Design Builder es una de las herramientas más conocidas en el medio para realizar simulaciones térmicas dinámicas; utiliza para tal fin el motor de cálculo que provee EnergyPlus, ya mencionado en las notas. https://designbuilder.co.uk

\begin{tabular}{|c|c|c|c|c|c|c|}
\hline Zona climática & Ciudad & Latitud & Longitud & Altitud (msnm) & Temp. mínima media $\left({ }^{\circ} \mathrm{C}\right)$ & Temp. máxima media $\left({ }^{\circ} \mathrm{C}\right)$ \\
\hline Subtropical litoral & 1. Ilo & $-17,69^{\circ}$ & $-71,34^{\circ}$ & 22 & 17,03 & 21,64 \\
\hline Desértica & 2. Tacna & $-18,05^{\circ}$ & $-70,28^{\circ}$ & 469 & 14,49 & 23,28 \\
\hline Continental templada & 3. Moquegua & $-17,19^{\circ}$ & $-70,94^{\circ}$ & 1517 & 13,05 & 22,16 \\
\hline \multirow[t]{2}{*}{ Continental fría } & 4.1. Arequipa & $-16,32^{\circ}$ & $-71,55^{\circ}$ & 2520 & 8,96 & 21,56 \\
\hline & 4.2. Cuzco & $-13,55^{\circ}$ & $-71,98^{\circ}$ & 3249 & 5,64 & 19,12 \\
\hline Continental muy fría & 5. Juliaca & $-15,47^{\circ}$ & $-70,16^{\circ}$ & 3826 & $-1,09$ & 15,73 \\
\hline
\end{tabular}


templados y noches frescas, de baja humedad relativa y alta radiación solar. En la medida de una mayor altitud, entre los 2300 y los 3500 msnm, se presenta el clima continental frío, con días templados, noches frías y alta oscilación térmica.

Por encima de los 3500 msnm se identifica una quinta zona climática, continental y muy fría, en la que se presentan noches con temperaturas bajo cero, frente a días frescos y generalmente soleados.

Hacia la vertiente oriental, por debajo de los 2300 msnm, se ubican los dos últimos climas: la selva tropical alta y la selva tropical baja. Ambos presentan altas temperaturas diurnas, alta humedad relativa y abundantes precipitaciones. La principal diferencia entre ellas es la menor temperatura que se alcanza en las partes altas durante las noches. Las particularidades climáticas de estas regiones condicionan el protagonismo de la ventilación y la sombra como estrategias bioclimáticas, y el cerramiento se adapta a estas necesidades. La oscilación térmica varía en función de la altitud, que resulta menor en la medida en que se ubique en zonas más bajas. Las particularidades climáticas de estas regiones condicionan el protagonismo de la ventilación y la sombra como estrategias bioclimáticas, y el cerramiento se adapta a estas necesidades. En tal sentido, dichos climas no serán considerados en la presente investigación, asumiendo que la tierra ali- vianada resulta una alternativa válida en sí misma, siempre y cuando se consideren las estrategias bioclimáticas mencionadas y se resuelva el proyecto en términos estructurales y constructivos.

Se presenta en la tabla 1 la lista de las ciudades elegidas, junto con sus coordenadas, su altitud y la zona climática a la que pertenecen, mientras que en la figura 1 se muestra la ubicación de las ciudades sobre el mapa y en un corte esquemático.

Con base en los datos climáticos obtenidos, se presenta en la figura 2 la representación gráfica, sobre el ábaco psicrométrico, de las temperaturas medias mensuales de cada una de las ciudades
(1) Figura 1. Mapa y corte V esquemático del territorio peruano con la ubicación de las ciudades elegidas.

Fuente: elaboración propia (2019). CC BY

\section{(7) Figura 2. Ábacos}

(7) psicrométricos con representación de días típicos, zona de confort y estrategias de diseño.

Fuente: elaboración

propia a partir del software Psychrometric Chart (2019). CC BY.
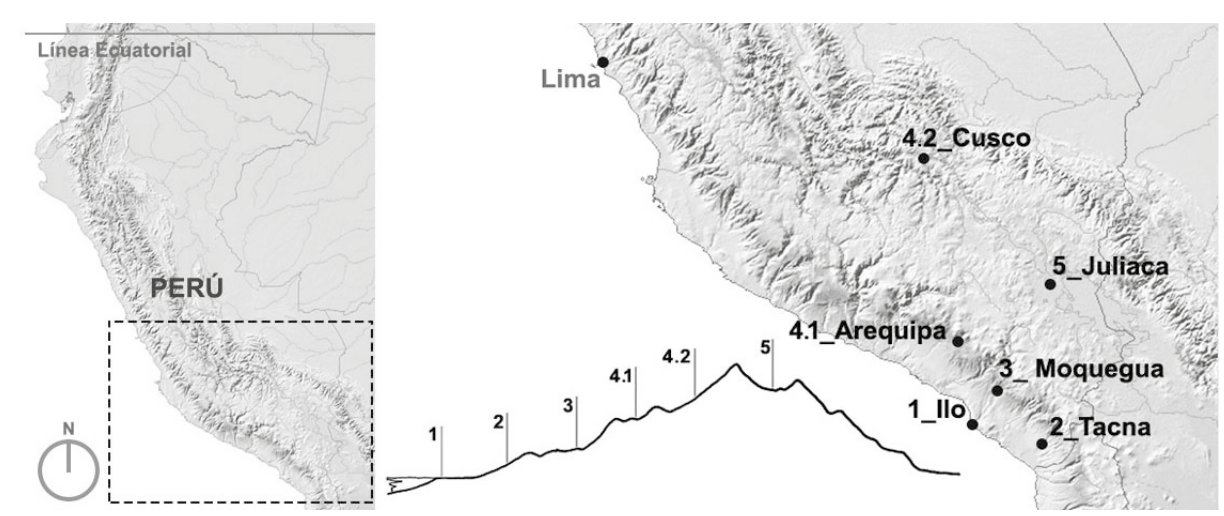

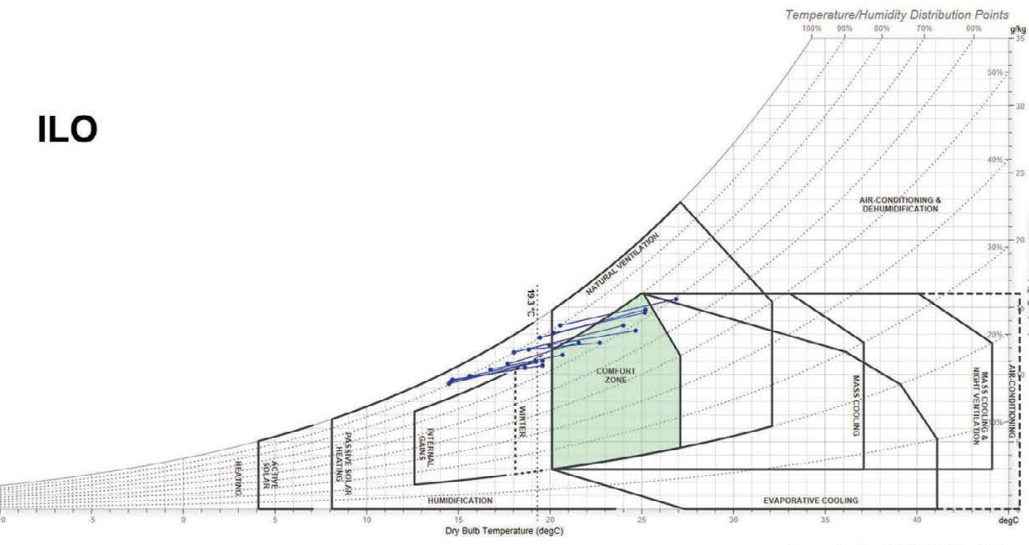

MOQUEGUA

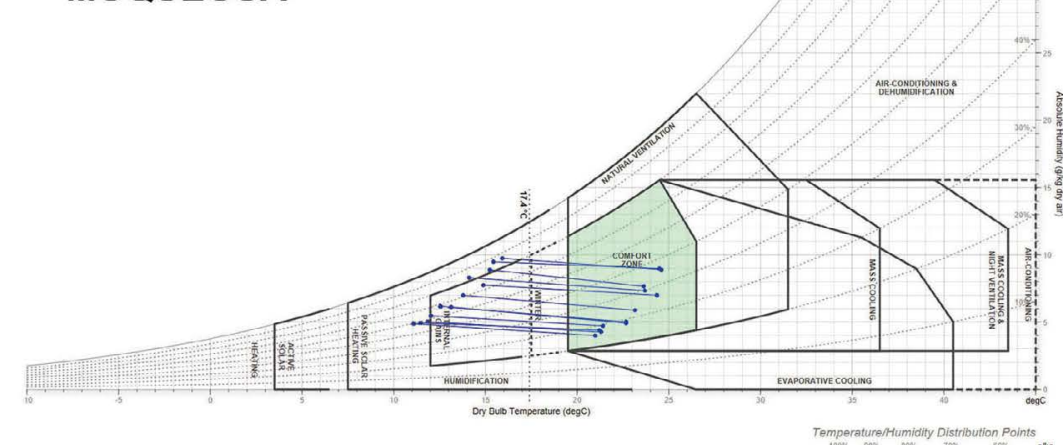

Cusco
TACNA

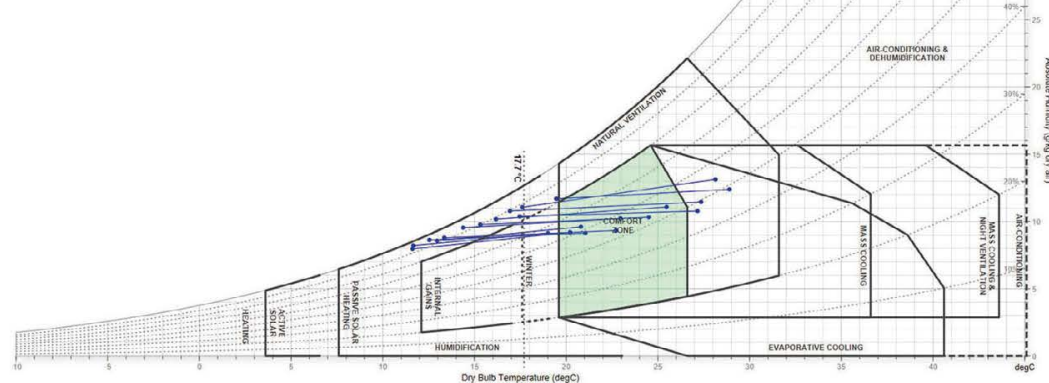

AREQUIPA

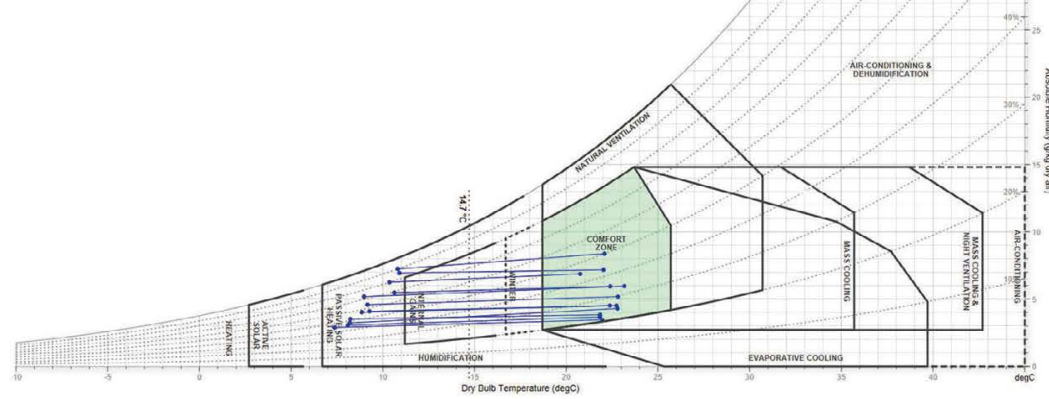

JULIACA
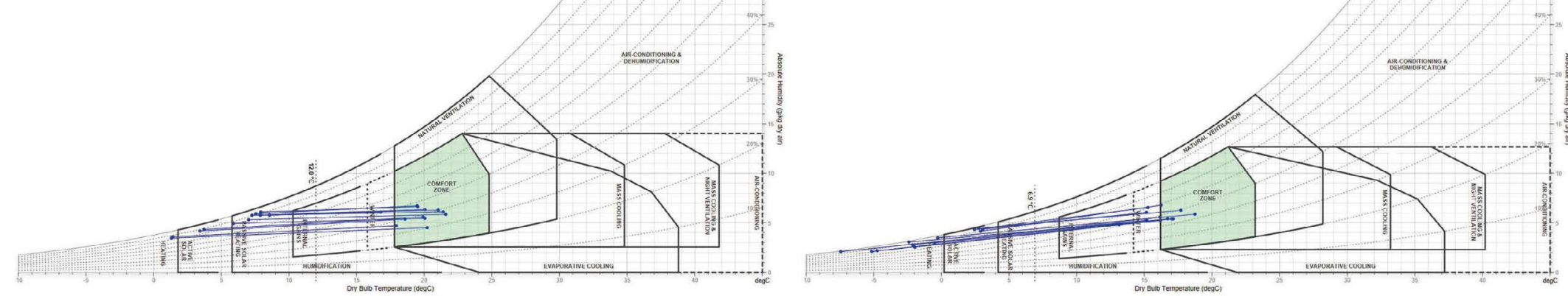

Vol. 
(A) Tabla 2. Valores de TE mensual, de TO y de los límites del rango aceptable de temperaturas en cada una de las localidades consideradas. Fuente: elaboración propia (2019).

\begin{tabular}{|c|c|c|c|c|c|}
\hline \multirow{2}{*}{$\begin{array}{l}\text { Zona climática } \\
\text { (localidad) }\end{array}$} & \multirow{2}{*}{ Mes } & \multirow{2}{*}{$\operatorname{TE}\left({ }^{\circ} \mathbf{C}\right)$} & \multirow{2}{*}{$\begin{array}{l}\text { TO } \\
\left({ }^{\circ} \mathrm{C}\right)\end{array}$} & \multicolumn{2}{|c|}{ Rango aceptable de temperatura $\left({ }^{\circ} \mathrm{C}\right)$} \\
\hline & & & & Límite inferior & Límite superior \\
\hline Subtropical litoral (llo) & Febrero & 23,15 & 24,80 & 22,35 & 27,25 \\
\hline Desértica (Tacna) & Febrero & 23,41 & 24,87 & 22,42 & 27,32 \\
\hline Continental templada (Moquegua) & Febrero & 19,54 & 23,88 & 21,43 & 26,33 \\
\hline Continental fría_1 (Arequipa) & Agosto & 14,58 & 22,62 & 19,17 & 26,07 \\
\hline Continental fría_2 (Cusco) & Agosto & 10,52 & 21,58 & 18,13 & 26,07 \\
\hline Continental muy fría (Juliaca) & Agosto & 7,71 & 20,87 & 17,42 & 24,32 \\
\hline
\end{tabular}
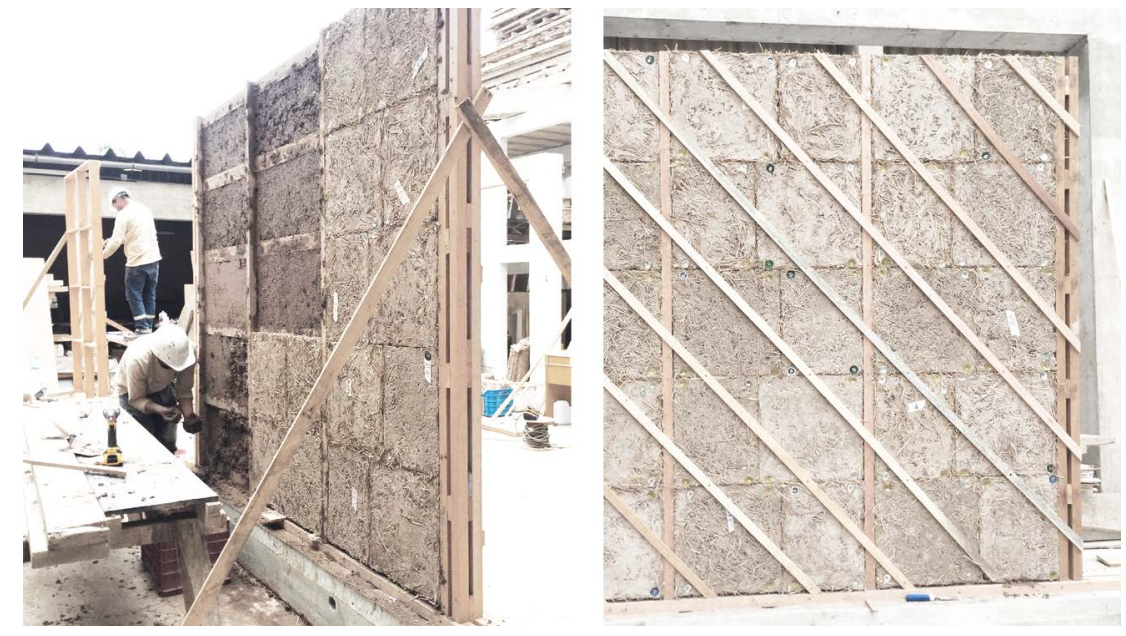

(A) Figura 3. Vistas del panel experimental con estructura de madera y elementos prefabricados de tierra alivianada.

Fuente: Centro Tierra, PUCP (2019). CC BY por Givoni (1998). elegidas. Sobre dichos ábacos, confeccionados con el software Psychrometric Chart, desarrollado por Marsh, A. (2019), se superponen la zona de confort y las estrategias de diseño sugeridas

La cercanía existente entre las líneas, en todos los casos, evidencia la poca oscilación térmica estacional que presentan todos los climas, debido a la proximidad de la línea ecuatorial. Así mismo, con excepción de la ciudad de Ilo, debido a su cercanía al mar, se aprecia una oscilación térmica diaria relativamente amplia, con temperaturas que van disminuyendo de manera evidente en la medida de la mayor altitud.

Las estrategias de diseño que sugieren los propios gráficos de la figura 2, indican para los climas más cálidos la necesidad de sombra y ventilación, mientras que para los climas fríos recomiendan tanto el aprovechamiento de las ganancias internas (hermeticidad y aislamiento) como de la ganancia solar de forma pasiva y activa. Cabe mencionar la utilidad de la presencia de materiales con gran masa térmica en climas de gran oscilación diaria de temperaturas, a la que se suma la necesidad del aislamiento para evitar las pérdidas de calor en climas fríos.

\section{Identificación de los límites de confort térmico}

Haciendo uso de la fórmula propuesta por De Dear y Brager (1998, p. 14) dentro del marco de la teoría del confort adaptativo, se deduce la temperatura operativa óptima (TO) de confort durante febrero y agosto, asociados a los meses más cálidos y más fríos del año, respectivamente, a partir de los valores de temperatura efectiva exterior promedio (TE). La fórmula mencionada es la siguiente:

$$
=18,9+(0,255 \times \mathrm{TE}){ }^{\circ} \mathrm{C}
$$

Para el caso de los climas cálidos y templados, interesa exclusivamente el comportamiento térmico del edificio en verano, mientras que para el caso de los climas fríos, lo que sucede durante el invierno. A partir de la temperatura óptima, se establecen los límites de temperatura interior aceptable para el $90 \%$ de los usuarios (TO +/$2,45^{\circ} \mathrm{C}$ ) en el caso de los climas cálidos y templados. Debido a la mayor rigurosidad de los climas fríos, y siempre siguiendo los principios del confort adaptativo, los límites en ellos se calculan para satisfacer al $80 \%$ de los usuarios (TO $+/-3,45^{\circ} \mathrm{C}$ ). Todos los valores de temperatura mencionados se presentan en la tabla 2.

Los resultados de los rangos de temperaturas interiores aceptables se utilizarán más adelante para valorar los resultados del desempeño térmico del modelo propuesto.

\section{Propiedades térmicas de la tierra alivianada}

En cuanto a las propiedades térmicas necesarias para caracterizar la tierra alivianada, se requirió la identificación de los valores de densidad $\left(\mathrm{kg} / \mathrm{m}^{3}\right)$, de conductividad térmica $(\mathrm{W} / \mathrm{m}-\mathrm{K})$ y de calor específico $(\mathrm{kJ} / \mathrm{kg}-\mathrm{K})$ de esta. Las densidades que se utilizarían en el proyecto fueron finalmente elegidas buscando la facilidad y la fiabilidad en la fabricación de los bloques, además de asegurar unas prestaciones térmicas mínimas. Las experiencias previas en proyectos de tierra alivianada (Wieser et al., 2018) permitieron elegir densidades de $600 \mathrm{~kg} / \mathrm{m}^{3}$ y de $800 \mathrm{~kg} / \mathrm{m}^{3}$, para los techos y los muros, respectivamente. La construcción de paneles experimentales de madera y tierra alivianada, concebidos dentro del marco del proyecto para someterlos a ensayos estructurales, permitió confirmar la idoneidad en la elección de la densidad de los elementos (figura 3).

En relación con los valores de calor específi$\mathrm{CO}$, estos fueron obtenidos a partir de los datos presentados por Volhard (2016, p. 201), y que, asociados a la propia densidad de las mezclas, indican valores de $1,10 \mathrm{~kJ} / \mathrm{kg}-\mathrm{K}$, para densidades entre $600 \mathrm{~kg} / \mathrm{m}^{3}$ y $1000 \mathrm{~kg} / \mathrm{m}^{3}$. 
Respecto a la conductividad térmica, se ha comprobado, igualmente, la existencia de una relación directa muy estrecha entre dicha conductividad y la densidad de las mezclas. Los valores compilados por Volhard (2016, p. 200), tanto de normas como de investigaciones previas, al igual que el estudio específico al respecto realizado por Wieser, Onnis y Meli (2018, p. 205), evidencian dicha relación.

En este último estudio se demostró que, a pesar de las diversas variables que intervienen y de los procedimientos manuales que involucran, es posible predecir con bastante precisión la conductividad térmica de las mezclas de tierra alivianada a partir de una fórmula de interpolación exponencial. Aplicando esa fórmula a las densidades de $600 \mathrm{~kg} / \mathrm{m}^{3}$ y $800 \mathrm{~kg} / \mathrm{m}^{3}$, los valores de conductividad térmica utilizados en el presente estudio fueron de 0,113 y $0,150 \mathrm{~W} / \mathrm{m}^{2 \circ} \mathrm{C}$, respectivamente.

\section{Propiedades térmicas de los sistemas constructivos}

Los diferentes sistemas constructivos tradicionales en el Perú responden a los climas locales, a la disponibilidad de materiales y a la condición sísmica de las regiones. Es así como existe cierta variedad de soluciones; aquella basada en el muro de adobe es la más utilizada en casi todas las regiones, salvo en los climas tropicales de la selva y la costa norte, cálidos y húmedos, y en los que se utiliza, generalmente, la madera. Al adobe se le suman la quincha (entramado de cañas recubiertas con barro) en las zonas costeras cercanas al litoral, el tapial, generalmente en zonas más altas y frías, y la piedra, en las regiones más frías de la puna.

Pero desde hace unas décadas, principalmente en las ciudades, y cada vez más rápido, se están incorporando materiales industrializados, como el ladrillo cocido, las bloquetas de concreto y la calamina metálica. Se construye prácticamente de la misma forma en la puna fría, en el desierto cálido-seco y en la llanura amazónica cálido-húmeda: con muros delgados de ladrillo hueco y grandes superficies traslúcidas. La mayor ligereza de las construcciones, sin la adición de capas aislantes y sin el nivel de hermeticidad apropiado, está generando serios problemas de confort térmico y crecientes gastos de energía en la medida en que condicionan un mayor uso de sistemas artificiales de control ambiental (aire acondicionado y calefacción).

Considerando los valores previamente obtenidos de la tierra alivianada, en la tabla 3 se presentan las propiedades térmicas de los diferentes materiales que conforman los muros y los techos que serán considerados en los cálculos posteriores. Los valores aproximados han sido obtenidos de Szokolay (2012) y de la CIBSE$^{9}$ (2015).

A partir de las características presentadas de los materiales, se calcularán en el siguiente título tanto los valores de inercia y de transmitancia térmica de los componentes como el desempeño térmico dinámico de cuatro propuestas constructivas. Dichas propuestas, que se analizarán de manera comparativa en las cinco zonas climáticas descritas, son las siguientes: a) edificio con muros de ladrillo hueco dispuesto de soga y techo de losa aligerada, y que es la solución más recurrente de las últimas décadas; b) edificio con muros de adobe y techos con torta de barro, alternativa cada vez menos usada, aunque aún vigente en las zonas rurales del país, y (c. 1 y c.2) dos alternativas de estructura de tierra alivianada en muros y techos. Las propuestas se encuentran mejor detalladas en la tabla 4.

Se indican a continuación algunas consideraciones constructivas importantes adicionales que se tomarán en cuenta para la valoración posterior de los modelos evaluados.

9 The Chartered Institution of Building Services Engineers (CIBSE). https://www.cibse.org/
(1) Tabla 3. Características y especificaciones térmicas de los materiales involucrados. Fuente: elaboración propia (2019).

\begin{tabular}{|c|c|c|c|c|}
\hline Componente & Material & $\begin{array}{l}\text { Conductividad térmica, } \lambda \\
(\mathrm{W} / \mathrm{m}-\mathrm{K})\end{array}$ & Densidad, $\left(\mathrm{kg} / \mathrm{m}^{3}\right)$ & Calor específico, (kJ/kg-K) \\
\hline \multirow{4}{*}{ Muros } & Ladrillo hueco (tipo "King Kong") & 0,470 & 1045 & 0,80 \\
\hline & Enlucido de cemento-arena & 0,720 & 1860 & 1,20 \\
\hline & Adobe, densidad 1750 & 0,567 & 1750 & 1,00 \\
\hline & Enlucido de tierra interior/exterior & 0,804 & 2000 & 1,00 \\
\hline \multirow{10}{*}{ Techos } & Tierra alivianada, densidad 800 & 0,150 & 800 & 1,10 \\
\hline & Ladrillo pastelero & 0,440 & 1200 & 0,80 \\
\hline & Concreto de mezcla pobre & 1,130 & 1800 & 1,00 \\
\hline & Concreto armado (CA) & 1,630 & 2300 & 1,00 \\
\hline & Ladrillo de techo (LT) & 0,440 & 720 & 0,80 \\
\hline & Techo de CA $(10 \mathrm{~cm})+\mathrm{LT}(30 \mathrm{~cm})$ & 0,738 & 1115 & 0,85 \\
\hline & Enlucido de yeso & 0,510 & 1120 & 0,95 \\
\hline & Torta de barro, densidad 1750 & 0,567 & 1750 & 1,00 \\
\hline & Entablado de madera & 0,140 & 600 & 1,20 \\
\hline & Tierra alivianada, densidad 600 & 0,113 & 600 & 1,10 \\
\hline
\end{tabular}


En primer lugar, para el caso de los techos de los edificios ubicados en las zonas más cálidas (subtropical, desértica y continental templada), se considerará una cobertura final contra las lluvias que, bien sea de teja, de calamina o, incluso, de paneles fotovoltaicos, estará colocada sobre las propuestas presentadas, con una cámara de aire ventilada y ligeramente inclinada (figura 4; ver detalle en el corte y la perspectiva). Dicha cobertura no influirá sobre los cálculos de transmitancia, pero sí en los cálculos dinámicos de simulación, al generar sombra durante el día sobre el techo inferior. Para el caso de las zonas más frías (continental fría y continental muy fría), se prescindirá de dicha cobertura adicional, para permitir que el techo reciba la radiación.

En segundo lugar, los muros de tierra alivianada cuentan con una estructura de pies derechos y travesaños de madera. Debido a que los valores de conductividad térmica y de densidad de la madera son prácticamente los mismos que los de la tierra alivianada (tabla 3), además de representar un porcentaje mínimo del área total, se considerará el muro de material uniforme, sin puentes térmicos.

En todos los casos se considerará un piso de losa de concreto con un entablado de madera como superficie final. Solo en los casos de los 2 climas fríos, se considerará un aislamiento adicional mínimo equivalente a $10 \mathrm{~cm}$ de bloques de tierra alivianada de $600 \mathrm{~kg} / \mathrm{m}^{3}$ de densidad, que representa un valor de resistencia térmica aproximada de $0,885 \mathrm{~m}^{2 \circ} \mathrm{C} / \mathrm{W}$.

Por otra parte, los vanos de ventana, en todos los casos, tendrán acabados de vidrio simple y marco de madera, mientras que la puerta planteada hacia el exterior será de madera contraplacada; se adicionará una capa de aislamiento en el interior en el caso de los climas fríos.

\section{Características del prototipo}

Las características formales del prototipo para simular corresponden a las que serán consideradas en la construcción de este, dentro del marco del proyecto, y a escala real, dentro del campus de la universidad. Es un pequeño edificio que contiene un espacio cerrado, además de un baño y una zona de terraza. Sobrepuesto a una losa de cimentación de concreto, el ambiente por evaluar térmicamente será solo el espacio cerrado, al cual en adelante se denominará el módulo. Este tiene una planta cuadrangular, un área de aproximadamente $14 \mathrm{~m}^{2}$ y una altura interior de 2,5 m.

Se presentan a continuación la planta, el corte y la elevación del prototipo propuesto, así como una vista en perspectiva de este, generada por el software Design Builder (figura 4).

A pesar de que el prototipo no se trata específicamente de una vivienda, se le asignará un uso continuo, tanto diurno como nocturno, con presencia de dos usuarios en el interior del módulo $\left(\approx 0,14\right.$ personas $\left./ \mathrm{m}^{2}\right)$ desarrollando actividades sedentarias. La presencia de artefactos eléctricos y el régimen de iluminación artificial también coincidirán con un espacio de uso doméstico.

En la medida en que el módulo prescinde de sistemas de climatización artificial, es necesario que este se adapte de forma pasiva a los diferentes tipos de clima. En tal sentido, junto con la variante del doble techo ventilado, ya mencionada, se considerarán diferentes soluciones en la orientación de los vanos para efectos de protección o captación solar, además de ciertas particularidades en el régimen de ventilación natural. Las estrategias consideradas son bastante genéricas y alineadas a las presentadas previamente sobre los ábacos psicrométricos, siguiendo las pautas que propone Givoni (1998).

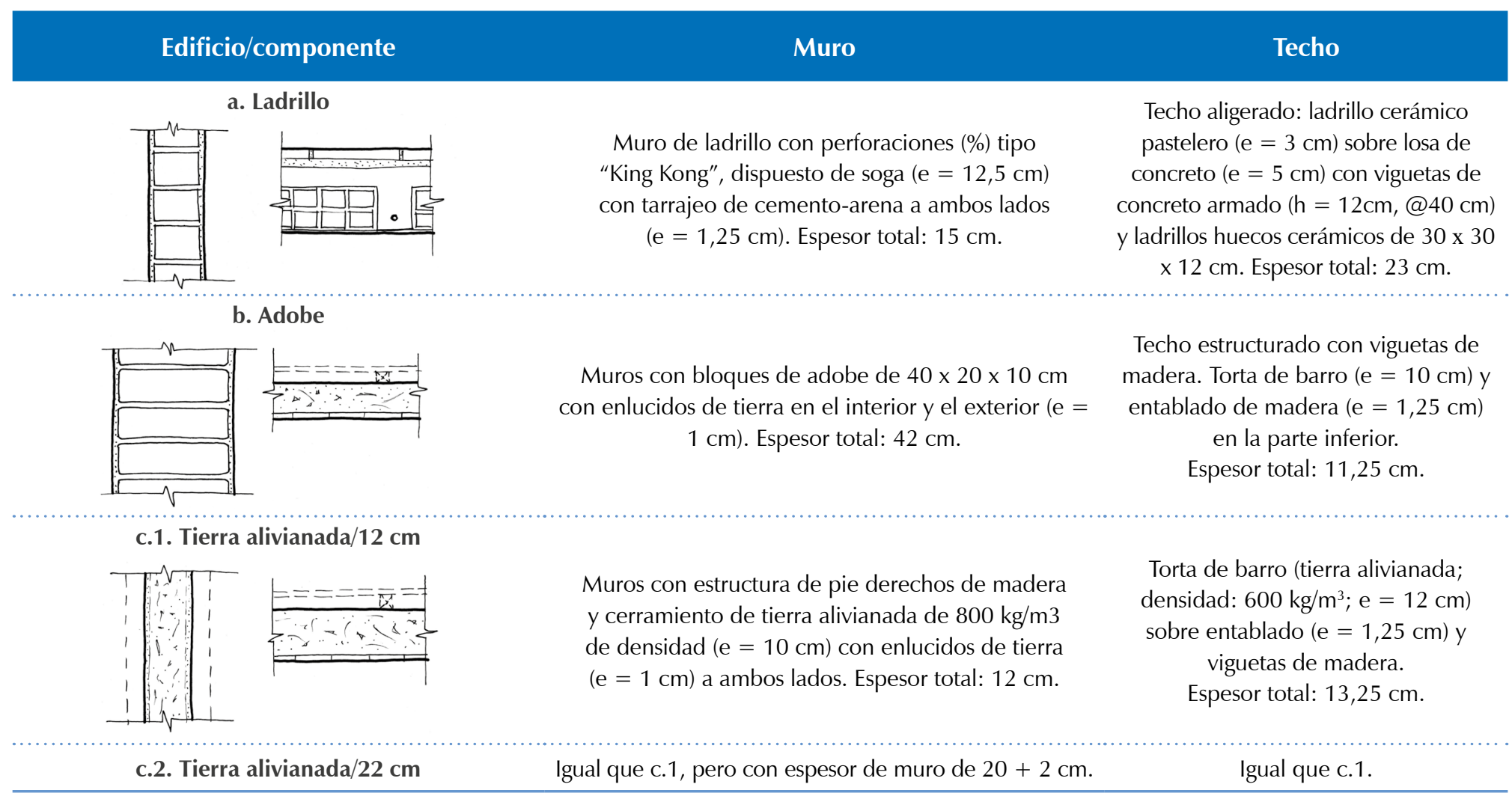


Para asegurar niveles óptimos de iluminación natural, se considera en todos los casos que el área traslúcida útil de los vanos equivale al 15\% del área del piso. Para el caso de los climas más cálidos, los vanos se ubicarán en las caras norte y sur, lo que asegura una buena ventilación, debido a la dirección de los vientos, y evita la incidencia solar directa sobre los vanos. A partir del clima continental templado, se prescinde del vano orientado hacia el sur y se lo pone en la cara este, lo que permite la ganancia solar en horas de la mañana. Finalmente, en los climas más fríos se concibe una claraboya de área equivalente en el centro del techo, para una mayor ganancia solar directa, de tal forma que compense la rigurosidad climática del emplazamiento. En estos últimos casos, se consideran, adicionalmente, unas contraventanas con aislamiento, que permanecerán cerradas durante las horas de la noche. En la tabla 5 se resumen de manera gráfica las variantes de doble techo ventilado y de la orientación de los vanos en función de los tipos de clima, según lo indicado en los párrafos previos.

En la medida en que está asegurada la operatividad de las ventanas, y debido a la ausencia de equipos de climatización artificial, la ventilación natural se acomodará en cada clima en función de la conveniencia de los usuarios. En los climas más cálidos, se permitirá la ventilación cuando el exterior esté más fresco que el interior y las temperaturas interiores salgan de la zona de confort. En los climas más fríos la ventilación estará limitada al mínimo requerido, permitiendo únicamente una infiltración que asegure una renovación de un cambio de aire por hora.

\section{Transmitancia e inercia térmicas de los cerramientos}

En una primera instancia, para identificar la capacidad de aislamiento de la envolvente, se calcula el valor de transmitancia térmica (Valor-U) de las distintas soluciones presentadas. Este valor resulta útil, ya que es de uso frecuente en normati- vas, pero cabe reconocer que ello responde más a una preocupación de ahorro de energía por el uso de sistemas artificiales. Adicionalmente, se identifica la inercia térmica de los elementos a partir de los valores de factor de decremento (Decrement Factor, en inglés) y tiempo de retardo (Time Lag, en inglés). Esta información es relevante, sobre todo, en edificios sin sistemas artificiales de climatización y en climas de gran oscilación térmica diaria, que, salvo la costa litoral, tienen en la inercia térmica de la envolvente una de sus principales estrategias de control ambiental.

La inercia térmica de un componente permite tener una idea de su capacidad para amortiguar y retardar el paso del calor desde y hacia el exterior del edificio. El tiempo de retardo indica el número de horas que el calor requiere para conducirse a través del elemento entre una cara y la otra; este valor ayuda a identificar el potencial de un componente en la medida en que puede retrasar, si el valor es sustancialmente alto, el paso del calor en los momentos más cálidos del
( Figura 4. Planta, corte y elevación esquemáticos del prototipo y vista en perspectiva.

Fuente: elaboración propia (2019). CC BY
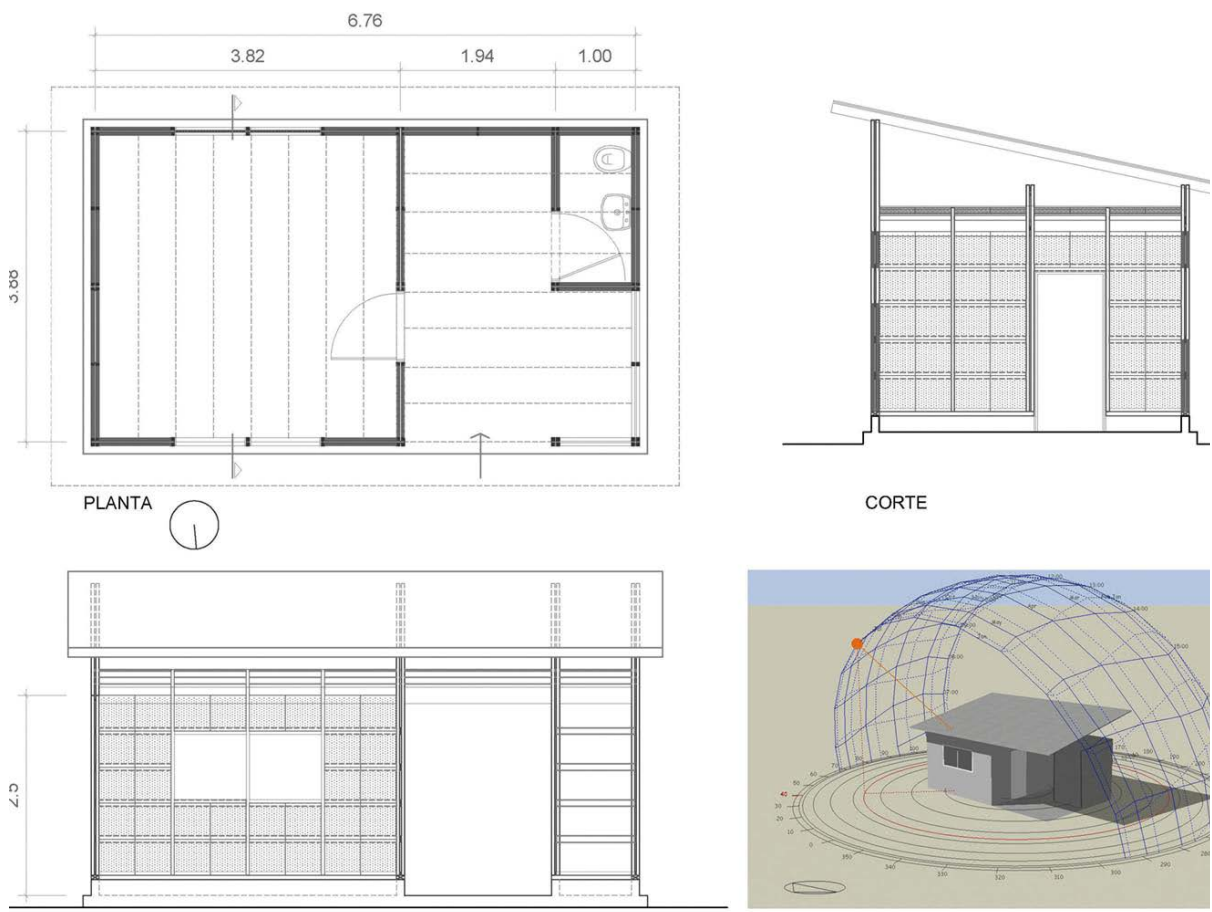

CORTE

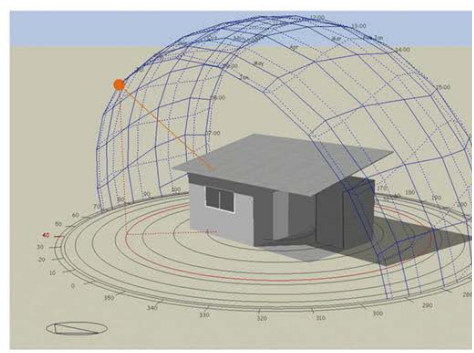

\begin{tabular}{ccccccc}
$\begin{array}{c}\text { Zona } \\
\text { climática }\end{array}$ & $\begin{array}{c}\text { Subtropical } \\
\text { litoral }\end{array}$ & Desértica & $\begin{array}{c}\text { Continental } \\
\text { templada }\end{array}$ & $\begin{array}{c}\text { Continental } \\
\text { fría_1 }\end{array}$ & $\begin{array}{c}\text { Continental } \\
\text { fría_2 }\end{array}$ & Continental muy fría \\
\hline Localidad & Ilo & Tacna & Moquegua & Arequipa & Cusco & Juliaca \\
\hline
\end{tabular}

Cubierta
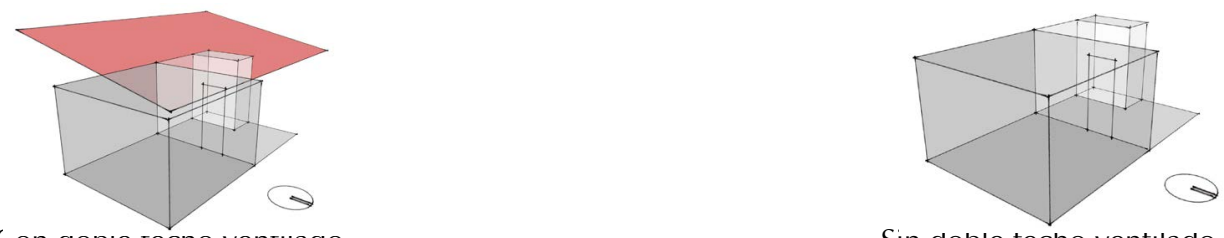

Con aopıe tecno venurado

Sin doble techo ventılado
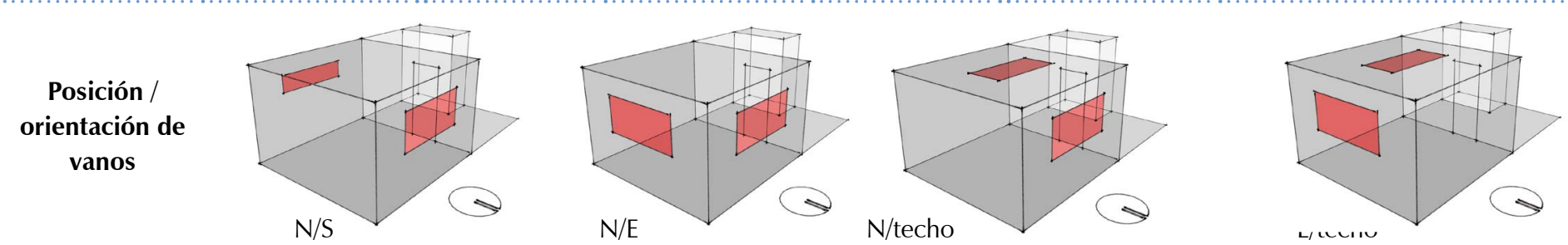

(A) Tabla 5. Variantes de diseño de cubierta y vanos en el módulo, según zona climática.

Fuente: elaboración propia (2019). 


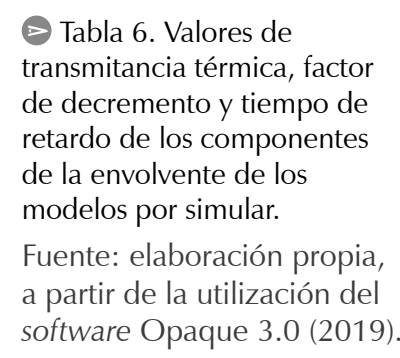

\begin{tabular}{|c|c|c|c|c|}
\hline \multicolumn{2}{|r|}{ Componente/valores } & $\begin{array}{c}\text { Transmitancia } \\
\text { térmica } \\
\left(\mathrm{W} / \mathbf{m}^{2 \circ} \mathrm{C}\right)\end{array}$ & $\begin{array}{c}\text { Factor de } \\
\text { decremento }\end{array}$ & $\begin{array}{c}\text { Tiempo de } \\
\text { retardo } \\
\text { (horas) }\end{array}$ \\
\hline \multicolumn{5}{|c|}{ Muros } \\
\hline a. & Muro de Ladrillo, e=15 cm & 2,170 & 0,82 & 3,63 \\
\hline b. & Muro de Adobe, $e=42 \mathrm{~cm}$ & 1,123 & 0,08 & 7,80 \\
\hline c. 1 & Muro de Tierra Alivianada, $800 \mathrm{~kg} / \mathrm{m}^{3}, \mathrm{e}=12 \mathrm{~cm}$ & 1,174 & 0,78 & 4,51 \\
\hline c.2 & Muro de Tierra Alivianada, $800 \mathrm{~kg} / \mathrm{m}^{3}, \mathrm{e}=22 \mathrm{~cm}$ & 0,659 & 0,33 & 10,13 \\
\hline \multicolumn{5}{|c|}{ Techos } \\
\hline a. & Techo aligerado de concreto, $e=23 \mathrm{~cm}$ & 2,005 & 0,48 & 6,21 \\
\hline b & Techo de torta de barro, $e=11.25 \mathrm{~cm}$ & 2,147 & 0,74 & 3,91 \\
\hline c.1. & 2. Techo de Tierra Alivianada $600 \mathrm{~kg} / \mathrm{m}^{3}, \mathrm{e}=13.25 \mathrm{~cm}$ & 0,740 & 0,68 & 5,31 \\
\hline
\end{tabular}

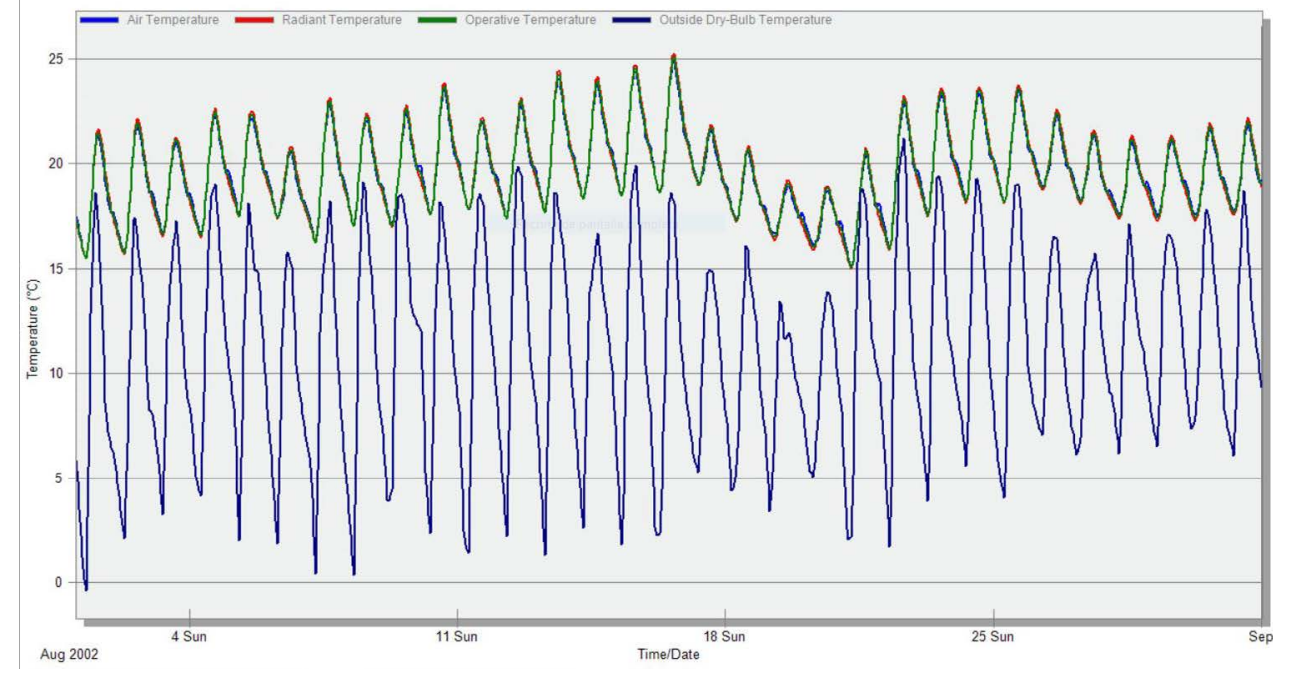

(4) Figura 5. Captura de imagen día y emitirlos durante los momentos más fríos. de resultados para el módulo de En el caso específico del factor de decremento, adobe, ubicado en la ciudad de el valor indica la relación entre la diferencia de Cuzco.

Fuente: elaboración propia, usando Design Builder 4.5 (2019). CC BY. temperaturas de la superficie interior frente a la diferencia de temperaturas de la superficie exterior. Un valor de 1 implicaría ausencia de masa térmica, mientras que un valor de 0 indicaría que las temperaturas superficiales interiores del elemento se mantienen constantes; seguramente, muy cercanas a la temperatura media exterior. Esta última situación, como ya se adelantó, suele ser muy útil en climas de alta oscilación térmica. Los resultados de las propiedades térmicas indicadas de los componentes se presentan en la tabla 6 .

Es importante añadir que la norma peruana vigente sobre ahorro de energía, EM.110 del Reglamento Nacional de Edificaciones (2014), aun siendo de aplicación opcional, establece que el valor de transmitancia térmica en los muros no debe superar los $2,36 \mathrm{~W} / \mathrm{m}^{2 \circ} \mathrm{C}$ en los climas menos rigurosos, ni los $1,00 \mathrm{~W} / \mathrm{m}^{2 \circ} \mathrm{C}$ en la zona altoandina. En los techos, el límite que establece la norma es de $2,20 \mathrm{~W} / \mathrm{m}^{2 \circ} \mathrm{C}$ en las zonas más bajas, y de $0,83 \mathrm{~W} / \mathrm{m}^{2 \circ} \mathrm{C}$ en la zona altoandina. Si bien existe una propuesta de actualización de la norma con valores un poco más exigentes, se puede observar que las soluciones tradicionales y convencionales logran cumplir con los requerimientos únicamente en los climas menos rigurosos.

\section{Simulaciones térmicas dinámicas}

Tomando en cuenta las consideraciones y los valores identificados en los títulos previos, en la figura 5 se presentan los resultados de una de las simulaciones térmicas dinámicas hechas con la herramienta informática Design Builder y los gráficos que resumen la temperatura interna promedio mensual de cada uno de los módulos, vinculada a la zona de confort identificada previamente considerando el método adaptativo (figura 6; figura 7). Los resultados corresponden a un día típico del mes más cálido para el caso de las localidades cálidas y templadas (Ilo, Tacna y Moquegua), y del mes más frío, para el de las localidades más altas y frías (Arequipa, Cuzco y Juliaca).

Finalmente, mientras que las figuras 6 y 7 muestran un día típico a partir de valores promedio mensuales, en la figura 8 se resumen, en porcentaje de tiempo, las condiciones de confort que se lograron en el interior de cada una de las alternativas constructivas a lo largo del mes crítico (el más cálido o el más frío, según el clima), considerando, nuevamente, la teoría de confort adaptativo.

\section{Discusión}

Los resultados obtenidos permiten, en términos generales, evidenciar notables diferencias en el comportamiento térmico de las distintas opciones constructivas analizadas. La identificación previa de la transmitancia y de la inercia térmicas de los componentes de muros y techos hizo prever dichos resultados. Las diferencias fueron más notables en la medida en que la exigencia del clima aumentaba, tanto por la mayor oscilación térmica diaria, debido a la continentalidad del emplazamiento, como por los valores de temperatura de los climas más fríos, debido a la altitud.

A partir de los valores de transmitancia obtenidos, tanto en los muros como en el techo, se confirma el alto grado de aislamiento que se alcanza con los elementos de tierra alivianada; estos son los únicos que logran cumplir con las exigencias de la actual norma peruana de eficiencia energética para el caso de los climas más fríos. Aun cuando es evidente que es posible 
cumplir las normas mencionadas a partir de la utilización de elementos aislantes artificiales e industriales, la tierra alivianada lo consigue manteniendo prestaciones de inercia térmica bastante buenos y con las ventajas ecológicas que implica el uso de materiales naturales.

Retomado los resultados de las simulaciones térmicas dinámicas, se puede observar que en los climas cálidos y templados todas las soluciones demostraron un buen comportamiento térmico frente a un día típico de verano. Esto se debe a la baja o moderada oscilación térmica y a unas temperaturas exteriores relativamente cercanas a la zona de confort. Esa condición se logró, igualmente, debido a la consideración de dos estrategias bioclimáticas fundamentales para este tipo de climas: la ventilación cruzada a demanda, que se consigue gracias a la operatividad de los vanos, y la protección efectiva de la radiación solar, debido a la orientación de las aberturas y a la disposición del doble techo ventilado.

Mientras que en las soluciones de envolvente con gran inercia térmica, como el adobe y la tierra alivianada gruesa, la condición de confort es plena y a toda hora en días particularmente cálidos, las soluciones ligeras presentan situaciones de disconfort por exceso de calor, aunque ello no deja de ser una condición poco recurrente. Cabe reconocer, en cualquiera de los casos, el papel del techo en el comportamiento térmico general, donde se destacan el alto nivel de inercia que tiene el techo aligerado en la construcción con ladrillo y el alto nivel de aislamiento de la cobertura de tierra alivianada.

En la medida en que los climas son más fríos, los materiales ligeros evidencian serias limitaciones a la hora de mantener el confort en horas de la noche y la madrugada. Es significativamente notorio lo que ocurre con la construcción de ladrillo, con casi la mitad del tiempo en situación de disconfort para el caso de la ciudad de Juliaca, la más alta y fría incluida en el presente trabajo. A pesar de contar con recursos pasivos para elevar la temperatura interior, esta termina muy por debajo de los límites mínimos requeridos. En relación con la solución de muros de tierra alivia- nada de $12 \mathrm{~cm}$, aun comportándose mejor que el ladrillo, esta resulta también insuficiente. En ambos casos, la causa principal es el bajo nivel de aislamiento que provee la envolvente.

Llama la atención el desempeño del módulo de adobe: aunque no presenta temperaturas tan bajas como las del módulo de ladrillo, la sensación de frío en el interior es una condición que ocurre muy a menudo: aproximadamente, la tercera parte del tiempo. Aun contando con una claraboya y un nivel de hermeticidad relativamente alto,
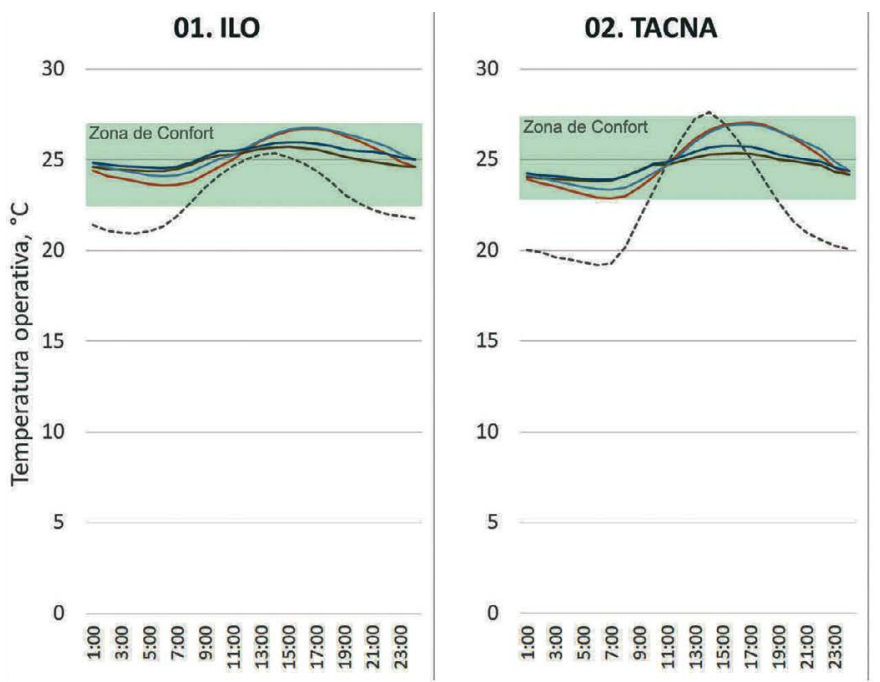

03. MOQUEGUA

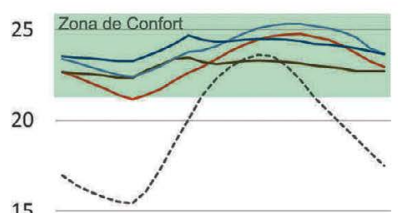
10 5

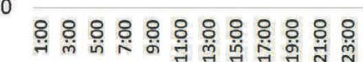

---Temp. Exterior -a. Ladrillo, $15 \mathrm{~cm} \quad$-b. Adobe, $42 \mathrm{~cm} \quad$-c.1. Tierra Alivianada, $12 \mathrm{~cm} \quad$-c.2. Tierra Alivianada, $22 \mathrm{~cm}$
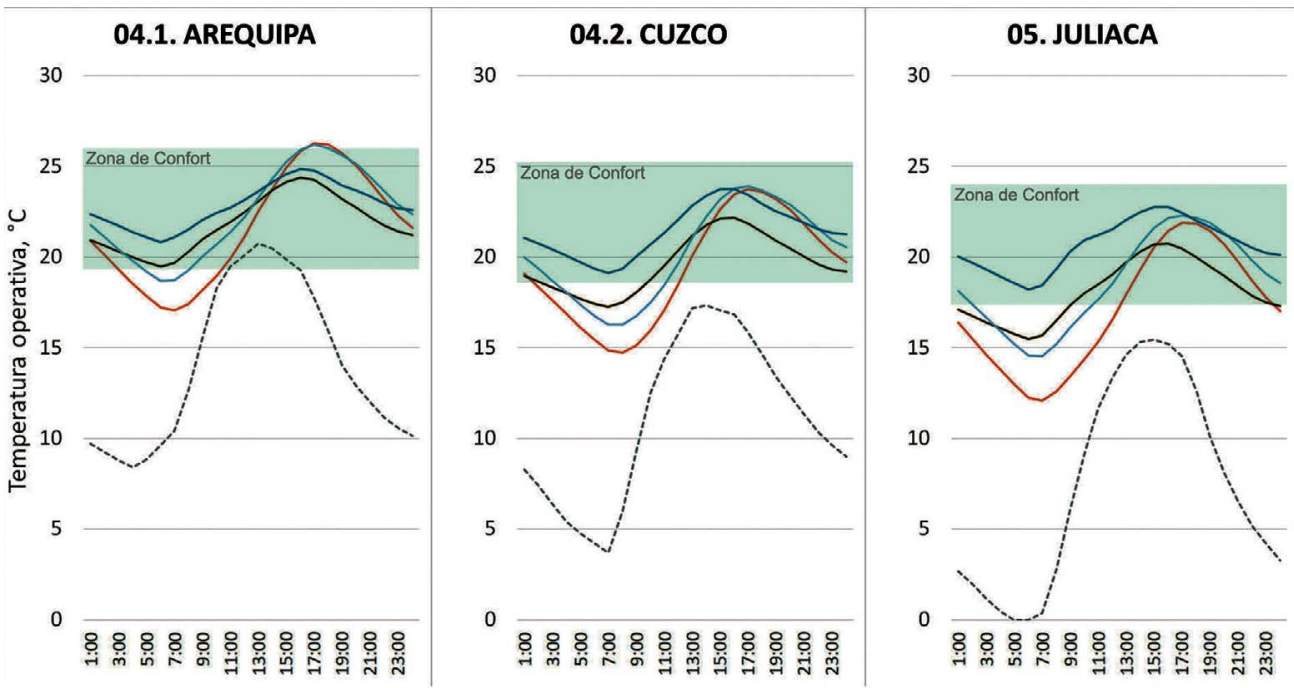

--- Temp. Exterior -a. Ladrillo, $15 \mathrm{~cm} \quad$-b. Adobe, $42 \mathrm{~cm} \quad$-c.1. Tierra Alivianada, $12 \mathrm{~cm} \quad$ c.2. Tierra Alivianada, $22 \mathrm{~cm}$

(A) Figura 7. Temperaturas exterior e interiores de cada módulo en localidades frías. Fuente: elaboración propia (2019). CC BY.

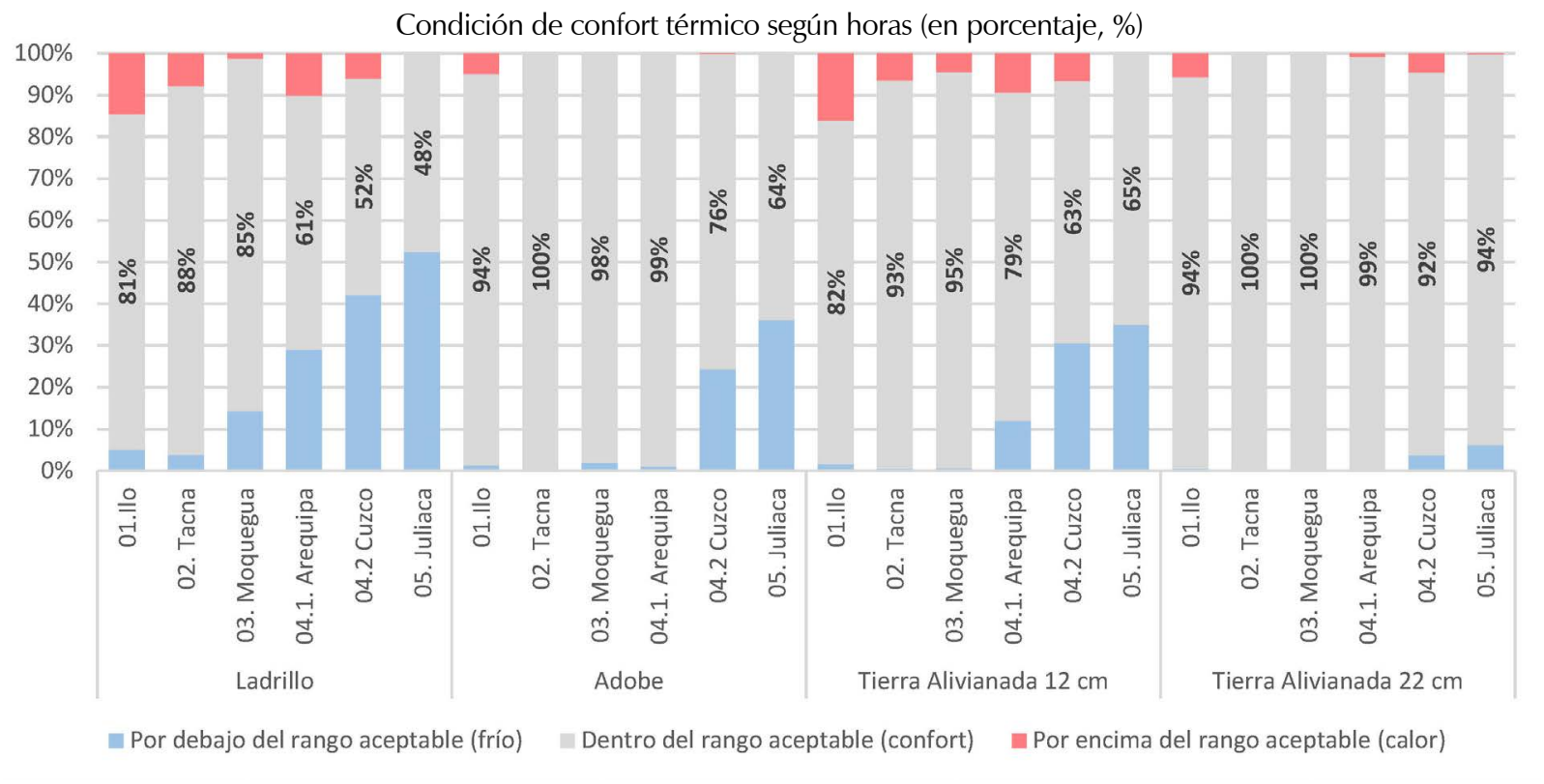

(A) Figura 8. Resultados comparativos de las cuatro soluciones constructivas. Fuente: elaboración propia (2019). CC BY. 
el gran espesor del muro no termina de lograr un nivel óptimo de aislamiento térmico, con resultados por debajo de las expectativas que este material suele ostentar.

La única solución que logra un buen desempeño térmico en el interior del módulo es la versión de muro grueso de tierra alivianada (espesor igual a $22 \mathrm{~cm}$ ). Con esta condición la temperatura interior, incluso en el clima más frío, se mantiene todo el tiempo en la zona de confort durante un día típico de invierno. Al igual que el adobe, se evidencia la capacidad para amortiguar las condiciones exteriores, debido a la masa que posee; pero la mayor capacidad de aislamiento de la tierra alivianada permite mantener más alta la temperatura todo el día.

\section{Conclusiones}

Las propiedades térmicas identificadas de las diferentes soluciones constructivas analizadas, además de las temperaturas obtenidas en las simulaciones dinámicas del módulo, permiten reconocer que la tierra alivianada, concebida como elemento que conforma la envolvente del edificio, se presenta como una alternativa válida y con un enorme potencial desde el punto de vista del desempeño térmico. Los resultados han sido satisfactorios y superiores a las demás soluciones en todos los climas considerados; sobre todo, en los más exigentes.

Las virtudes de la tierra alivianada, desde el punto de vista del desempeño térmico, se explican a partir del marcado equilibrio entre una masa térmica media y una conductividad térmica relativamente baja, condición poco común en elementos constructivos tradicionales y contemporáneos. A dicha condición se le suma la ventaja de estar compuesta de materiales naturales, renovables y biodegradables, todo lo cual la presenta como una alternativa constructiva con mucho potencial.

Motivos muy diversos hacen que las construcciones de ladrillo sean en la actualidad las más recurrentes en el país, en todos los ámbitos climáticos y para toda clase de edificios. Es importante reconocer el pobre desempeño térmico de este tipo de construcciones; sobre todo, en los climas más fríos y exigentes. En la medida en que se prescinde de capas adicionales de aislamiento, resulta imposible lograr ambientes interiores mínimamente confortables. $\mathrm{Y}$ aun cuando el desempeño térmico de un edificio tradicional de adobe es sensiblemente mejor que el de uno de ladrillo, este resulta también insuficiente en los climas fríos respecto a requerimientos de confort contemporáneos.

Por lo expuesto, resultará útil indagar en futuras investigaciones acerca de la viabilidad constructiva de la concepción de cerramientos de tierra alivianada o de la incorporación de capas adicionales de dicho material en los muros y los techos existentes, buscando mejorar el desempeño térmico de los edificios a partir de una solución económica y de bajo impacto en el medio ambiente.

\section{Agradecimientos}

Los autores agradecen al Servicio Nacional de Capacitación para la Industria de la Construcción (SENCICO), al Concejo Nacional de Ciencia, Tecnología e Innovación Tecnológica (CONCYTEC) y a la Pontificia Universidad Católica del Perú (PUCP), por el financiamiento que hizo posible el desarrollo de la presente investigación.

\section{Referencias}

Bouillon, C. P. (Ed.), Blanco, A., Fretes, V., Boruchowicz, C., Herrera, K., Medellín, N., Muñoz, A. y Azevedo, V. (2012). Un espacio para el desarrollo: Los mercados de vivienda en América Latina y el Caribe. Washington, D.C.: Banco Interamericano de Desarrollo. Recuperado de:

https://publications.iadb.org/publications/ spanish/document/Un-espacio-para-eldesarrollo-Los-mercados-de-vivienda-enAm\%C3\%A9rica-Latina-y-el-Caribe.pdf

Busbridge, R., \& Rhydwen, R. (2010). An investigation of the thermal properties of hemp and clay monolithic walls. Proceedings of Advances in Computing and Technology, (AC\&T) The School of Computing and Technology 5th Annual Conference, University of East London, pp. 163-170. Recuperado de: https://repository.uel.ac.uk/item/862v9

CIBSE, G. A. (2015). Guide A: Environmental design. London: Chartered Institution of Building Services Engineers CIBSE.

Climate.OneBuilding.Org (2019). Repository of free climate data for building performance simulation. Recuperado de: http://climate.onebuilding.org/

De Dear, R., y Brager, G. S. (1998). Developing an adaptive model of thermal comfort and preference. JournalASHRAE Transactions. 104(1),145-167. Recuperado de:: https://escholarship.org/uc/item/4qq2p9c6

Givoni, B. (1998). Climate considerations in building and urban design. New York: John Wiley \& Sons.

Instituto Geofísico del Perú (2018). El Clima en el Perú. Ministerio del Ambiente. Recuperado de:

http://www.met.igp.gob.pe/clima/

Marsh, A. (2019). Psychrometric Chart. Software en línea. Recuperado de:

http://andrewmarsh.com/software/psychrochart-web/

Reglamento Nacional de Edificaciones (2014). Norma EM.110 Confort térmico y lumínico con eficiencia energética. Ministerio de Vivienda, Construcción y Saneamiento del Perú. Recuperado de::

http://cdn-web.construccion.org/normas/ rne2012/rne2006/files/titulo3/04_EM/ DS006-2014_EM.110.pdf

Szokolay, S. (2012). Introduction to architectural science. Great Britain: Routledge. Recuperado de:

https://archive.org/details/Introduction to_Architectural_Science_The_Basis_ofSustainable_Design

U.S. Department of Energy (2019). EnergyPlus Weather Data. Recuperado de:: https://energyplus.net/weather
Vinceslas, T., Colinart, T., Hamard, E., de Ménibus, A. H., Lecompte, T., \& Lenormand, $H$. (2019). Light Earth Performances for Thermal Insulation: Application to Earth-Hemp. En Earthen Dwellings and Structures (pp. 357-367). Singapore: Springer.

Volhard, F. (2016). Light earth building. A handbook for building with wood and earth. Basilea, Suiza: Birkhäuser.

Wieser, M. (2011). Consideraciones bioclimáticas en el diseño arquitectónico: el caso peruano. Lima: Centro de Investigación de la Arquitectura y la Ciudad. PUCP. Recuperado de:: http://repositorio.pucp.edu.pe/index/ handle/123456789/28699

Wieser, M., Onnis, S. y Meli, G. (2018). Conductividad térmica de la tierra alivianada con fibras naturales en paneles de quincha. SIACOT 2018 Tierra, Cultura, hábitat resiliente y desarrollo sostenible, $18^{\circ}$ Seminario iberoamericano de arquitectura y construcción en tierra. Ciudad de La Antigua, Guatemala: Pro Terra. Recuperado de:: http://files.pucp.edu.pe/facultad/arquite ctura/2019/11/27173426/2018-SIACOTWieser-Onnis-Meli.pdf 


\section{Vol.}
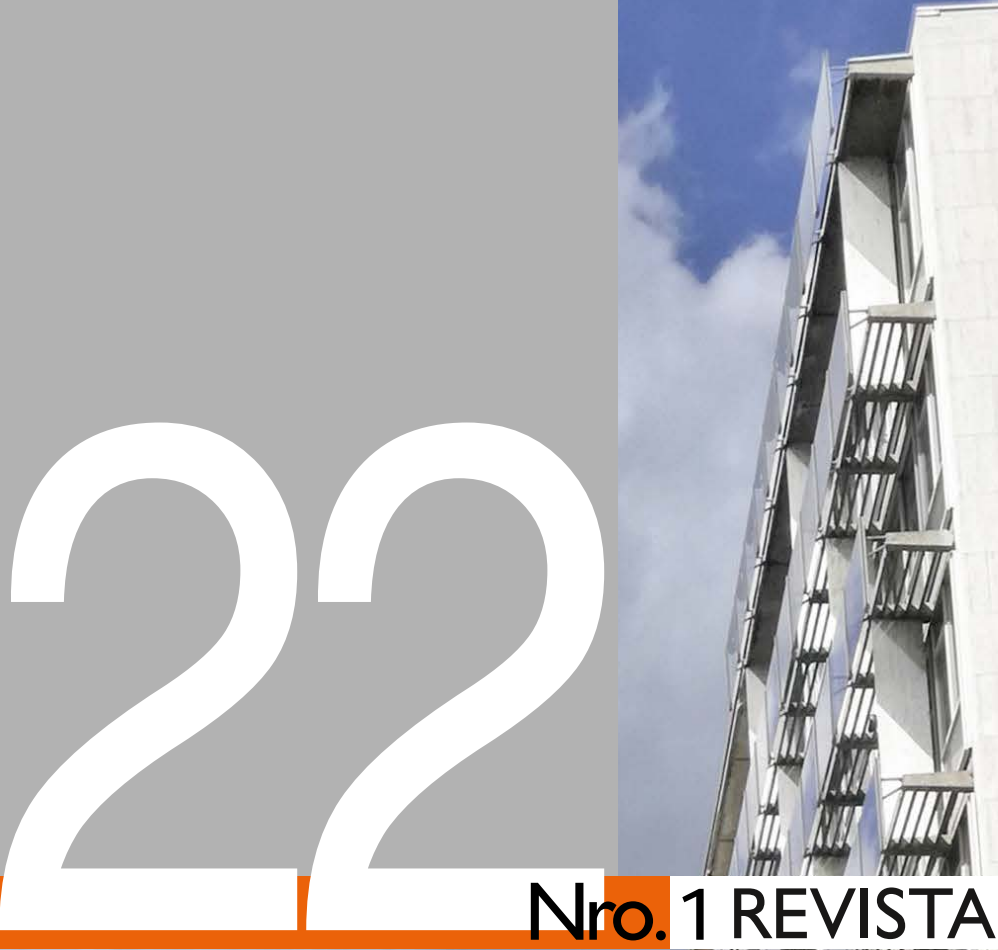

ISSN: 1657-0308 (Impresa)

Nro. 1 REVISTA DE ARQUITECTURA

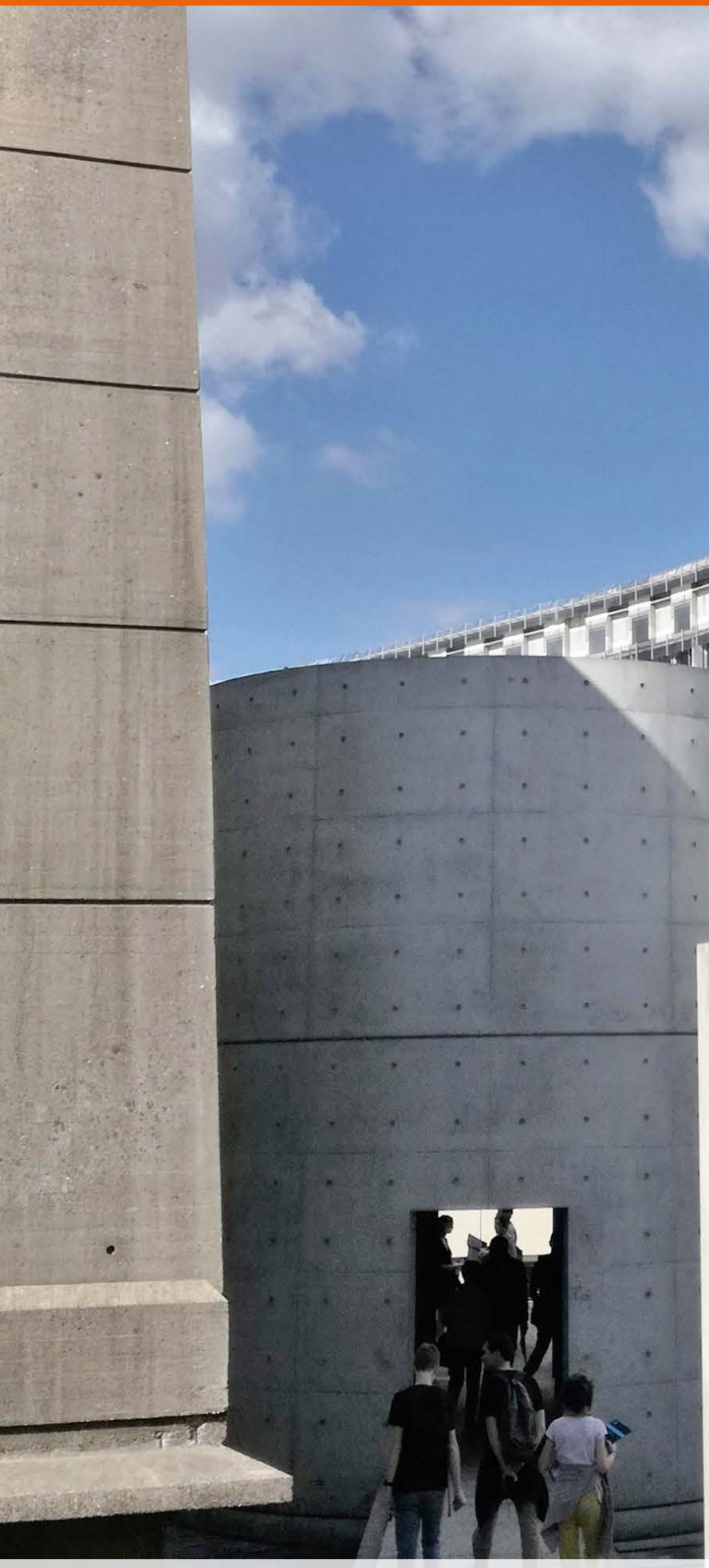

$\overline{9}$
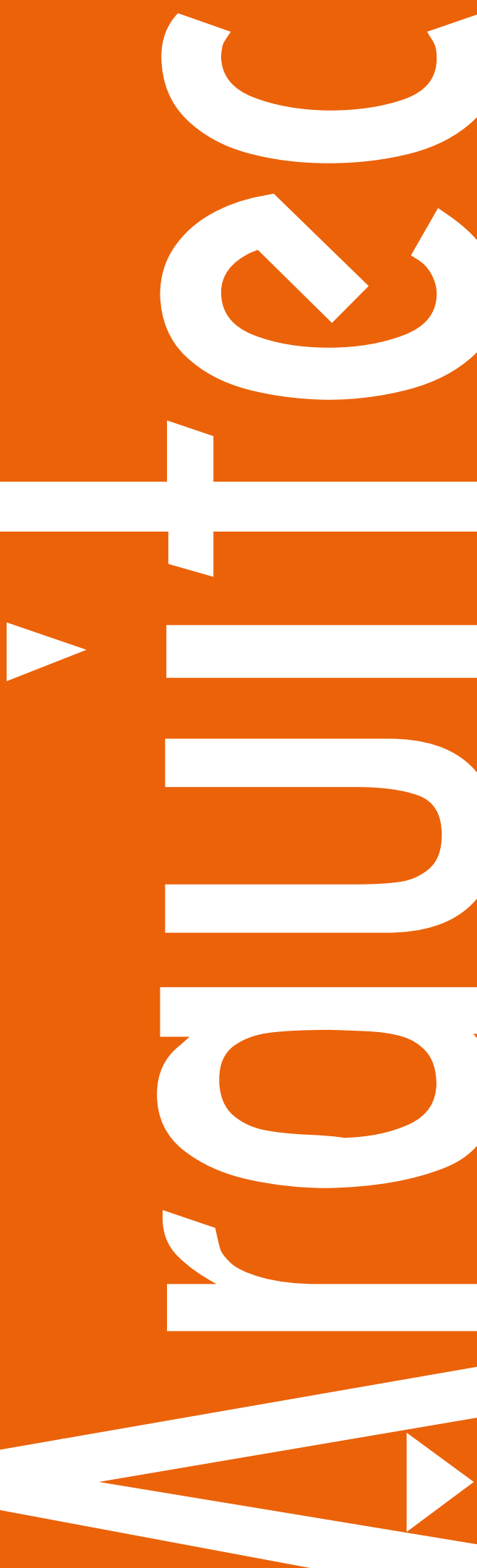


\section{Enfoque y alcance}

La Revista de Arquitectura (Bogotá) ( (ISSN 1657-0308 Impresa y E-ISSN 2357-626X en línea) es una publicación científica seriada de acceso abierto, arbitrada mediante revisión por pares (doble ciego) e indexada, en donde se publican resultados de investigación originales e inéditos.

Está dirigida a la comunidad académica y profesional de las áreas afines a la disciplina. Es editada por la Facultad de Diseño y el Centro de Investigaciones (CIFAR) de la Universidad Católica de Colombia en Bogotá (Colombia).

La principal área científica a la que se adscribe la Revisto de Arquitectura (Bogotá) según la OCDE es:

Gran área: 6. Humanidades

Área: 6.D. Arte

Disciplina: 6D07. Arquitectura y Urbanismo

También se publican artículos de las disciplinas como 2A02, Ingeniería arquitectónica; 5C03, Estudios urbanos (planificación y desarrollo); 6D07, Diseño.

Los objetivos de la Revista de Arquitectura (Bogotá) son:

- Promover la divulgación y difusión del conocimiento generado a nivel local, nacional e internacional

- Conformar un espacio para la construcción de comunidades académicas y la discusión en torno a las secciones definidas.

- Fomentar la diversidad institucional y geográfica de los autores que participan en la publicación.

- Potenciar la discusión de experiencias e intercambios científicos entre investigadores y profesionales.

- Contribuir a la visión integral de la arquitectura, por medio de la concurrencia y articulación de las secciones mediante la publicación de artículos de calidad.

- Publicar artículos originales e inéditos que han pasado por revisión de pares, para asegurar que se cumplen las normas éticas, de calidad, validez científica, editorial e investigativa.

- Fomentar la divulgación de las investigaciones y actividades desarrolladas en la Universidad Católica de Colombia.
Palabras clave de la Revista de Arquitectura (Bogotá): arquitectura, diseño, educación arquitectónica, proyecto y construcción, urbanismo.

Idiomas de publicación: español, inglés, portugués y francés. Título abreviado: Rev. Arquit.

\section{Titulo corto: RevArq}

\section{Políticas de sección}

La revista se estructura en tres secciones correspondientes a las líneas de investigación activas y aprobadas por la institución, y dos complementarias, que presentan dinámicas propias de la Facultad de Diseño y las publicaciones relacionadas con la disciplina.

Cultura y espacio urbano. En esta sección se publican los artículos que se refieren a fenómenos sociales en relación con el espacio urbano, atendiendo aspectos de la historia, el patrimonio cultural y físico, y la estructura formal de las ciudades y el territorio.

Proyecto arquitectónico y urbano. En esta sección se presentan artículos sobre el concepto de proyecto, entendido como elemento que define y orienta las condiciones proyectuales que devienen en los hechos arquitectónicos o urbanos, y la forma como estos se convierten en un proceso de investigación y nuevo de conocimiento. También se presentan proyectos que sean resultados de investigación, los cuales se validan por medio de la ejecución y transformación en obra construida del proceso investigativo. También se contempla la publicación de investigaciones relacionadas con la pedagogía y didáctica de la arquitectura, el urbanismo y el diseño.

Tecnología, medioambiente y sostenibilidad. En esta sección se presentan artículos acerca de sistemas estructurales, materiales y procesos constructivos, medioambiente y gestión, relacionados con los entornos social-cultural, ecológico y económico.

Desde la Facultad. En esta sección se publican artículos generados en la Facultad de Diseño, relacionados con las actividades de docencia, extensión, formación en investigación o internacionalización, las cuales son reflejo de la dinámica y de las actividades realizadas por docentes, estudiantes y egresados; esta sección no puede superar el $20 \%$ del contenido.

Textos. En esta sección se publican reseñas, traducciones y memorias de eventos relacionados con las publicaciones en Arquitectura y Urbanismo.
A Frecuencia de publicación

Desde 1999 y hasta el 2015, la Revista de Arquitectura (Bogotá) publicó un volumen al año, a partir del 2016 se publicarán dos números por año en periodo anticipado, enero-junio y julio-diciembre, pero también maneja la publicación anticipada en línea de los artículos aceptados (versión Post-print del autor).

La Revista de Arquitectura (Bogotá) se divulga mediante versiones digitales (PDF, HTML, EPUB, XML) e impresascon un tiraje de 700 ejemplares, los tiempos de producción de estas versiones dependerán de los cronogramas establecidos por la editorial.

Los tiempos de recepción-revisión-aceptación pueden tardar entre seis y doce meses dependiendo del flujo editorial de cada sección y del proceso de revisión y edición adelantado.

Con el usuario y contraseña asignados, los autores pueden ingresar a la plataforma de gestión editorial y verificar el estado de revisión, edición o publicación del artículo.

\section{A Canje}

La Revista de Arquitectura (Bogotá) está interesada en establecer canje con publicaciones académicas, profesionales o científicas del área de Arquitectura y Urbanismo, como medio de reconocimiento y discusión de la producción científica en el campo de acción de la publicación.

\section{Mecanismo}

Para establecer canje por favor descargar, diligenciar y enviar el formato: RevArq FP20 Canjes
Universidad Católica de Colombia (2020, enero-junio). Revista de Arquitectura (Bogotá), 22(I) I-188. Doi: 10.14718

ISSN: 1657-0308 E-ISSN: 2357-626X

Especificaciones:

Formato: $34 \times 24 \mathrm{~cm}$

Papel: Mate $115 \mathrm{~g}$

Tintas: Negro y policromía
A Contacto

Dirección postal:

Avenida Caracas No. 46-72.

Universidad Católica de Colombia

Bogotá D.C.(Colombia)

Código postal: 111311

Facultad de Diseño Centro de Investigaciones (CIFAR). Sede El Claustro. Bloque " $\mathrm{L}$ ", 4 piso Diag. 46A No. $15 \mathrm{~b}-10$ Editor, Arq. César Eligio-Triana

Teléfonos:

+57 (1) $3277300-3277333$

Ext. 3109; 3112 o 5146

Fax: +57 (1) 2858895
Correo electrónico: revistadearquitectura@ucatolica.edu.co cifar@ucatolica.edu.co

Página WEB: www.ucatolica.edu.co vínculo Revistas científicas

http://publicaciones.ucatolica.edu.co revistas-cientificas http://editorial.ucatolica.edu.co/ojsucatolica/revistas ucatolica/index.php/RevArq 
